\title{
Gut microbiota composition is associated with narcolepsy type 1
}

Alexandre Lecomte, MSc, Lucie Barateau, MD, Pedro Pereira, PhD, Lars Paulin, MSc, Petri Auvinen, PhD, Filip Scheperjans, MD, and Yves Dauvilliers, MD

Neurol Neuroimmunol Neuroinflamm 2020;7:e896. doi:10.1212/NXI.0000000000000896

\section{Abstract}

\section{Objective}

To test the hypothesis that narcolepsy type 1 (NT1) is related to the gut microbiota, we compared the microbiota bacterial communities of patients with NT1 and control subjects.

\section{Methods}

Thirty-five patients with NT1 (51.43\% women, mean age $38.29 \pm 19.98$ years) and 41 controls ( $57.14 \%$ women, mean age $36.14 \pm 12.68$ years) were included. Stool samples were collected, and the fecal microbiota bacterial communities were compared between patients and controls using the well-standardized $16 \mathrm{~S}$ rRNA gene amplicon sequencing approach. We studied alpha and beta diversity and differential abundance analysis between patients and controls, and between subgroups of patients with NT1.

\section{Results}

We found no between-group differences for alpha diversity, but we discovered in NT1 a link with NT1 disease duration. We highlighted differences in the global bacterial community structure as assessed by beta diversity metrics even after adjustments for potential confounders as body mass index (BMI), often increased in NT1. Our results revealed differential abundance of several operational taxonomic units within Bacteroidetes, Bacteroides, and Flavonifractor between patients and controls, but not after adjusting for BMI.

\section{Conclusion}

We provide evidence of gut microbial community structure alterations in NT1. However, further larger and longitudinal multiomics studies are required to replicate and elucidate the relationship between the gut microbiota, immunity dysregulation and NT1.

\author{
Correspondence \\ Dr. Dauvilliers \\ ydauvilliers@yahoo.fr
}




\section{Glossary}

BMI = body mass index; EDS = excessive daytime sleepiness; $\mathbf{I Q R}=$ interquartile range; $\mathbf{N T 1}$ = Narcolepsy type 1 ; MSLT = Multiple Sleep Latency Test; ORX = orexin; OTU = operational taxonomic unit; SOREMP = sleep-onset REM periods.

Narcolepsy type 1 (NT1) is an orphan disorder characterized by excessive daytime sleepiness (EDS), cataplexy, hypnagogic hallucinations, sleep paralysis and disturbed nighttime sleep. $^{1-3}$ This sleep disease is associated with psychiatric, cardiovascular, autonomic and metabolic disorders. ${ }^{3} \mathrm{NT} 1$ is also called orexin (ORX)/hypocretin deficiency syndrome, as it is caused by the irreversible loss of ORX neurons in the lateral hypothalamus. ${ }^{4,5}$ Patients subsequently need lifelong management with symptomatic medications. ${ }^{6,7}$ The precise underlying process leading to this destruction remains unclear; however, several arguments strongly support an autoimmune origin, ${ }^{8}$ with the tight association with immunerelated genetic factors, mainly the HLA $D Q B 1{ }^{*} 06: 02$ allele, the T-cell receptor alpha, and specific adaptative immune response directed to ORX neurons. ${ }^{9-11}$ The rarity of familial cases and the low concordance rate between monozygotic twins highlight the key role of environmental factors in the etiology of NT1. ${ }^{6,12}$ Well-designed environmental studies are rare in NT1 with low reproducibility, except for the recently discovered triggers H1N1 influenza infection and vaccination during the 2009 influenza pandemic. ${ }^{13,14}$ An association with Streptococcus pyogenes infections was also reported in NT1, with high anti-streptolysin $\mathrm{O}$ titers when close to disease onset, ${ }^{8}$ but it was not replicated in a recent study. ${ }^{15}$ Although studies proving causality between environmental factors and NT1 are rare, it has been hypothesized that infections can trigger the development of the disease by molecular mimicry and bystander activation mechanisms. ${ }^{11}$

The gut microbiota is home to an estimated 100 trillion bacteria, archaea, fungi and other microbial eukaryotes, as well as viruses, with the total genome estimated to contain approximately 3 million genes, 100 -fold more than the human genome. $^{16,17}$ These organisms have evolved to live in symbiosis with their human host. However, the composition of the gut microbiome has the potential to influence pathogenesis of many disorders including neuro(auto)immune diseases (e.g., MS and neuromyelitis optica spectrum) and neurodegenerative diseases (e.g., Parkinson's disease, Alzheimer's disease, Huntington's disease) through the microbiota-gutbrain axis, and more widely, obesity, diabetes, liver diseases and cancer ${ }^{18,19}$ A growing body of evidence demonstrates the complex interactions between the gut microbiota and the CNS. $^{18-20}$

Recent advancements with application of high-throughput sequencing technology (e.g., 16S rRNA gene sequencing ${ }^{21}$ ) allowed to identify many of the unculturable microorganisms that constitute the human gut microbiota. Differences in microbiota diversity and relative abundance have been reported in neuroimmune diseases. ${ }^{18-20}$ However, whether gut microbiota dysbiosis is causal or a contributing factor, involved in onset and/or progression of the disease remains unclear for most of these disorders. ${ }^{18-20}$

Assessment of the intestinal microbiome in NT1 is a new field of investigation. The potential role for gut microbiota in the pathogenesis of NT1 remains an open question, as well as the possible, yet hypothetical, presence of a specific microbial signature. To explore this hypothesis, we compared the fecal microbiota bacterial communities of well-defined patients with NT1 and control subjects using a 16S rRNA gene amplicon sequencing approach.

\section{Methods}

\section{Standard protocol approvals, registrations, and patient consents}

This study was approved by the local ethics committees (Comité de Protection des Personnes, France: Constitution of a cohort and of a clinical, neurophysiologic and biological bank of rare hypersomnolence disorders). All adult participants and both parents for minors provided written informed consent prior to participation.

\section{Study population}

Thirty-five patients with NT1 (51.43\% women, mean age: $38.29 \pm$ 19.98 years, 5 children $>12$ y.o.) diagnosed at the National Reference Center for Narcolepsy, Montpellier, France were recruited from March 2018 to February 2019. The diagnosis of NT1 was based on the third International Classification of Sleep Disorders (ICSD-3) criteria $^{22}$ : presence of EDS for at least 3 months, mean sleep latency $\leq 8$ minutes on the Multiple Sleep Latency Test (MSLT), with at least 2 sleep-onset REM periods (SOREMPs), and typical cataplexy or low CSF levels of ORX-A $(<110 \mathrm{pg} / \mathrm{mL})$ when a lumbar puncture was performed. All patients were positive for HLA-DQB1*66:02. CSF ORX-A level was determined in 29 (83\%) patients in duplicate using the ${ }^{125}$ I-radioimmunoassay (RIA) kit from Phoenix Pharmaceuticals, Inc., (Burlingame, CA) according to the manufacturer's recommendations. All had low levels of ORX-A. Patients were systematically evaluated for body mass index (BMI) (categorized as normal weight $\left[<25 \mathrm{~kg} / \mathrm{m}^{2}\right]$, overweight $\left[25-30 \mathrm{~kg} / \mathrm{m}^{2}\right]$, and obese $\left[\geq 30 \mathrm{~kg} / \mathrm{m}^{2}\right]$, and according to BMI growth curves for children), age at disease onset and disease duration, and medication intake at time of the study. None of these patients had significant comorbid psychiatric or medical disorders.

We also recruited 41 controls (57.14\% women, mean age: 36.14 \pm 12.68 years, 4 children $>12$ y.o.) during the same period: 
18 (44\%) were healthy controls selected from the general population via advertisement and local association networks, and 23 (56\%) had an initial EDS complaint, but none of them fulfilled criteria for a central hypersomnolence disorder (including narcolepsy). These 23 subjects had no objective sleepiness on the MSLT (mean sleep latency >8 minutes), no SOREMP, no abnormalities on nocturnal polysomnography, no complaint of long sleep time, no medication use, and no other significant psychiatric, neurologic, or medical disorders.

None of the participants (NT1 and C) were affected with comorbid neurologic inflammatory or immune pathologies. None of them were treated with antibiotics, immunotherapy, or corticosteroids at the time of the study.

\section{Stool sampling}

Stool samples were collected for all participants in the sleep unit from March 2018 to February 2019 using DNA Stool Collection Tubes containing DNA Stabilizer from the PSP ${ }^{\circledR}$ Spin Stool DNA Plus Kit of STRATEC Molecular ${ }^{\circledR}$, and subsequently frozen and stored at $-80^{\circ} \mathrm{C}$. Stool samples were shipped on dry ice to the DNA Sequencing and Genomics laboratory at the Institute of Biotechnology, University of Helsinki, Finland for $16 \mathrm{~S}$ rRNA gene analysis.

\section{DNA extraction}

DNA extraction of the samples was performed using the STRATEC Molecular ${ }^{\circledR}$ PSP Spin Stool DNA Plus Kit according to the manufacturer's instructions. Samples were randomized between extraction batches to minimize batch effects. Blank extractions were performed from DNA Stabilizer tubes with no addition of template as a way to assess the presence of possible contaminants.

\section{Library preparation and sequencing}

Libraries were obtained by performing 2 steps of PCR. In the first step the V3-V4 regions of the 16S rRNA gene were amplified following a previously published protocol. ${ }^{23,24}$ We used 2 technical replicates ( $25 \mu \mathrm{L}$ reactions) per subject sample, and a mixture of the universal bacterial primers $341 \mathrm{~F} 1-4 \quad\left(5^{\prime}\right.$ CCTACGGGNGGCWGCAG $\left.3^{\prime}\right)$ and 785R1-4 (5' GACTACHVGGGTATCTAATCC $3^{\prime}$ ) with partial TruSeq adapter sequences added to the $5^{\prime}$ end. ${ }^{23}$ PCR was done with the following conditions: initial denaturation at $98^{\circ} \mathrm{C}$ for 30 seconds, 12 cycles at $98^{\circ} \mathrm{C}$ for 10 seconds, $55^{\circ} \mathrm{C}$ for 30 seconds, $72^{\circ} \mathrm{C}$ for 10 seconds, and a final extension at $72^{\circ} \mathrm{C}$ for 5 minutes. A cleanup step was performed to remove unused primers and nucleotides following a previously published protocol. ${ }^{24}$ In the second PCR step the full-length P5 and P7 Illumina adapters containing 8 bp indexes (dual-index) were added. The used indexes were selected using BARCOSEL. ${ }^{25}$ The two-step PCR and subsequent quantification, pooling, and purification were done as described previously. ${ }^{24}$ The obtained PCR amplicon pool was checked using Fragment Analyzer (Advanced Analytical Technologies Inc., Ankeny, IA). PCR of the samples and the isolation controls were done in batches and every PCR batch included a blank control (no added DNA template for amplification) to assess potential contamination. Finally, the PCR products were sequenced with Illumina MiSeq using the v3 600 cycle kit paired-end ( $325 \mathrm{bp}+285 \mathrm{bp})$. All the samples were sequenced in a single run to avoid batch effects. The raw sequence data contained a total of $24,660,868$ paired-end reads.

\section{Sequencing data}

Primers were removed from the reads using cutadapt (version $2.3)^{26}$ with default parameters, an error rate of $10 \%$, minimum length of overlap between read and adapter set as $3 \mathrm{bp}$, with command line provided in supplementary data (Supplementary methods, links.lww.com/NXI/A322). The reads were paired, quality trimmed, taxonomically classified, and clustered into operational taxonomic units (OTUs) following Mothur's Standard Operating Procedure (SOP) for MiSeq (Mothur 1.42.1; SOP version last updated on April 4, 2018). ${ }^{27}$ We inspected the extraction and PCR blanks, which overall had very low amounts of sequence reads, and since these did not suggest any overall problems with contamination, we removed these samples before downstream analysis. The final sequence data set (without the blanks) consisted of 7,460,575 good quality reads.

\section{Statistical analysis}

All statistical comparisons and data visualization were performed with the $\mathrm{R}$ statistical programming language (v. 3.6.1). ${ }^{28}$ Quantitative variables are presented as mean and $\mathrm{SD}$, or median with interquartile range (IQR). All $p$-values are double-tailed, with statistical significance accepted at an alpha of 0.05 in alpha and beta diversity, and at an alpha of 0.1 in differential abundance analysis.

Non-rarefied data without singletons were used for calculating alpha diversity indices (observed richness, Shannon index and Inverse Simpson). These 3 different indices were compared statistically between groups using the Wilcoxon rank sum test, and Spearman's rank correlation test. Beta diversity, based on Bray-Curtis dissimilarity, was performed with rarefied data $(37,008$ sequences per sample). Beta diversity was visualized with Non-Metric Multidimensional Scaling and compared statistically with adonis2 (an implementation of PERMANOVA) from the vegan package. ${ }^{29}$

Differential abundance analyses were done with DESeq2, which uses Generalized Linear Models with a negative binomial distribution, with Benjamini-Hochberg method for multiple comparisons correction. A complementary differential abundance analysis was done with ALDEx $2,{ }^{31}$ which uses a Dirichletmultinomial model to infer abundance from counts. Predicted metagenomic functional potential of the microbial community was obtained by using PICRUSt2 (v. 2.3.0 beta) (Phylogenetic Investigation of Communities by Reconstruction of Unobserved States), ${ }^{32,33}$ and following the tutorial available on GitHub. Visualization and statistical comparison of differential abundances in predicted metagenomic functional potential was performed using STAMP (v. 2.1.3) (statistical analysis of taxonomic and functional profiles) ${ }^{34}$ and following PICRUSt 
Figure 1 NMDS ordination plot of the control (C) and narcolepsy (NT1) samples

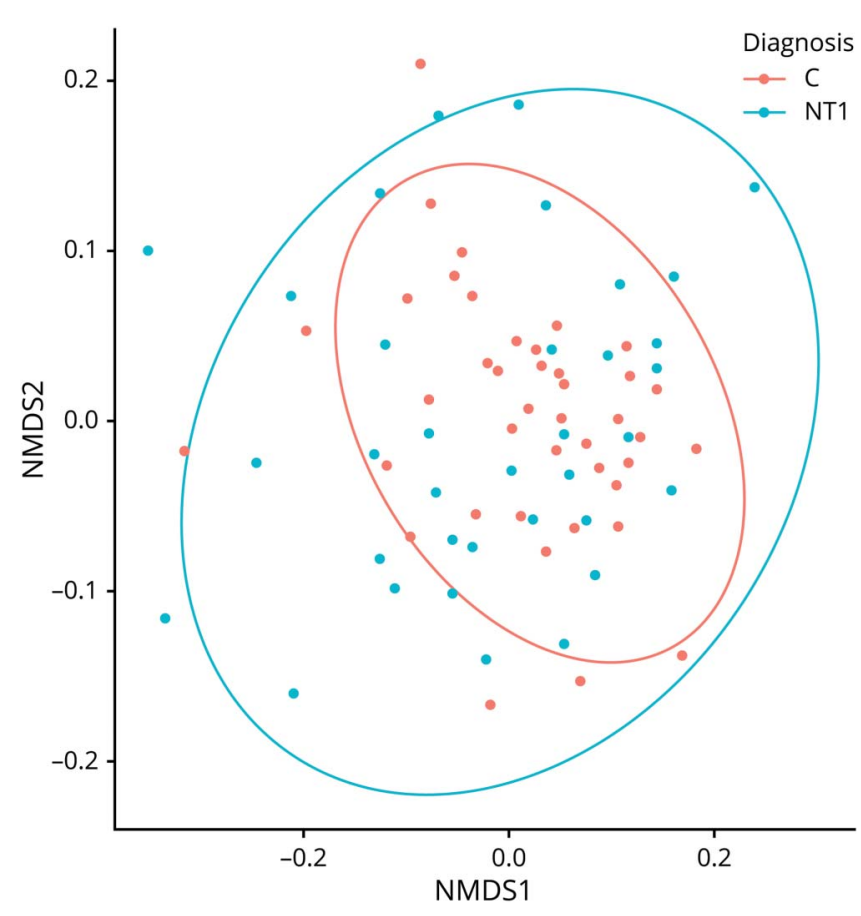

Ordination based on Bray-Curtis dissimilarity calculated with genus-leve data, randomly rarefied to 37,008 sequences per sample. Ellipses indicate $95 \%$ confidence intervals. Each point represents one sample. The closer the points are to one another, the more similar the microbiome compositions of the samples are. NMDS = Non-Metric Multidimensional Scaling; NT1 = Narcolepsy type 1.

visualization and statistics in STAMP provided in PICRUSt tutorial. EC (Enzyme Classification) and KEGG (Kyoto Encyclopedia of Genes and Genomes) Ortholog pathway predictions were analyzed after correction for multiple comparisons (Benjamini-Hochberg FDR).

\section{Data availability}

Anonymized data not provided in the article because of space limitations will be shared by request from any qualified investigator.

\section{Results}

\section{Characteristics of the study population}

At the time of the study, the duration of NT1 was $221.5 \pm 198.8$ months. Thirteen patients (37\%) had a normal BMI, 12 (34\%) were overweight and $10(29 \%)$ were obese. At time of study entry, 26 patients were drug-free while 9 were treated for narcolepsy: modafinil $(n=4)$, methylphenidate $(n=5)$ alone or in combination with pitolisant $(n=1)$, sodium oxybate $(n=1)$, venlafaxine $(n=3)$ and clomipramine $(n=1)$.

Healthy controls and the control population with a complaint of EDS did not significantly differ for age, gender and BMI, and neither in alpha nor beta diversity. Thus, both control populations were combined to form a single larger control group. Initial analysis revealed that with respect to microbiome compositional data, one control subject was a major outlier for unknown reasons. We chose to not include this control subject in subsequent analyses. We found no betweengroup differences for age and gender between patients with NT1 and controls. However, BMI was higher in patients than controls (median [IQR]: 26.2 [23.3-30.3] vs 23.1 [20.6-24.2], $p<0.001)$.

\section{Alpha diversity}

Alpha diversity defined as microbial community richness and evenness did not differ between patients with NT1 and controls as assessed with the Shannon (Wilcoxon rank sum test: $p=0.07814, \mathrm{~W}=887$ ) and Inverse Simpson (Wilcoxon rank sum test: $p=0.06801, \mathrm{~W}=893$ ) indices, nor with observed richness (Wilcoxon rank sum test: $p=0.1281, \mathrm{~W}=864$ ). Alpha diversity was also investigated as function of age, gender and BMI, with no significant effects found (Supplementary table 1, links.lww.com/NXI/A321).

We further analyzed in patients with NT1 the association between alpha diversity and demographic and clinical characteristics such as gender, age, disease duration, BMI, and medication (Supplementary table 2, links.lww.com/NXI/ A321). We found no associations except between the Shannon index (i.e., a commonly used index to characterize diversity in terms of richness and evenness) and disease duration (Spearman's rank correlation test: $p=0.038, r=0.352$ ).

\section{Beta diversity}

Beta diversity quantifies the community composition dissimilarity between samples and showed significant differences between patients and controls using Bray-Curtis dissimilarity in univariable PERMANOVA models $\left(p=0.026, R^{2}=0.023\right.$ ) (figure 1$)$. We also found trends for dissimilarity for gender $\left(p=0.0549, R^{2}=\right.$ $0.02)$ and BMI $\left(p=0.082, R^{2}=0.019\right)$, but not for age, disease duration and medication. The difference between patients and controls remained significant after adjustment for gender and BMI in a multivariable model (Diagnosis: $p=0.027, R^{2}=0.023$; Gender: $p=0.032, R^{2}=0.022$; BMI: $p=0.055, R^{2}=0.02$ ).

We further analyzed the Beta diversity in patients with NT1 in univariable models as a function of gender, age, disease duration, $\mathrm{BMI}$, and medication, but found no significant associations.

\section{Differential microbial abundance analyses between patients with NT1 and controls}

The data set was composed of 7,243 non-singleton OTUs distributed into 180 genera, 73 families, 36 orders, 22 classes and 12 phyla. The 20 most common and the 5 most abundant genera (e.g., Bacteroides, Faecalibacterium, Roseburia, Prevotella, and Ruminococcus) in patients and controls are shown in figure 2 . We analyzed the differential abundance at different taxonomic levels, namely OTU, genus, family, and phylum levels with DESeq2. For every taxon level, we identified and plotted the normalized counts and the relative abundances of 

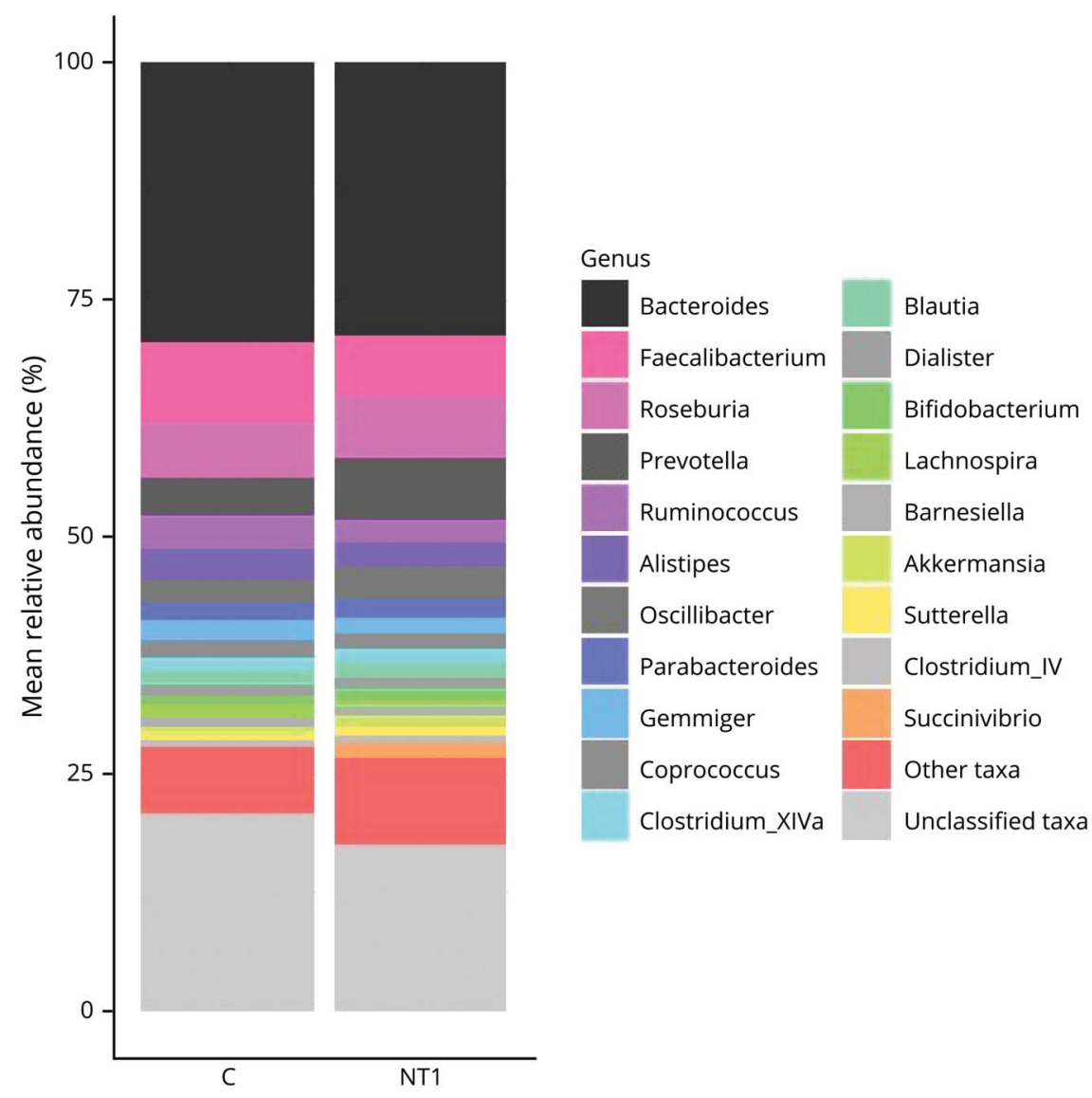

Mean relative abundance of 20 most common genera organized as control (C) and patient (NT1) groups. NT1 $=$ Narcolepsy type 1 .

the significant differentially abundant taxa if any, the 20 most common taxa, as well as the 20 taxa with the lowest corrected $p$-value for multiple comparisons. We found several taxa with differential abundance between patients with NT1 and controls (table 1 and figure 3). Bacteroides Otu00012 and Bacteria unclassified Otu00078 were decreased in NT1 compared to controls, while Flavonifractor Otu00099 and Bacteroidetes unclassified Otu00102 were increased in NT1 compared to controls. After adjusting for gender, 3 among the 4 taxa remained significant between groups: Bacteroides Otu00012, Bacteria unclassified Otu00078 and Flavonifractor Otu00099. However, after correction for BMI alone, and then gender and BMI in the same model, no taxa remained statistically significant for differential abundance between groups. Few other between-group differences were identified at OTU, genus, family and phylum taxonomic levels. However, a detailed review of the normalized counts plots and the relative abundance plots showed several outliers in both groups and thereafter these taxa could no longer be considered as different between the groups.

A complementary differential abundance analysis was done with ALDEx2 at all taxonomic levels; however we found no significant differences between groups in any of the comparisons performed.

\section{Relative microbial abundance analyses according to demographic and clinical characteristics in patients with NT1}

We analyzed the differential abundance analysis at genus level within patients with NT1 according to age (in children compared to adults), disease duration (population divided as the median of disease duration, adjusted only for age), BMI (population divided into obese, non-obese), and medication (in untreated and then in treated patients). Among these subgroups, DESeq2 identified the following taxa as differentially abundant (Age: Acidaminococcus, Allisonella, Alloprevotella, Catenibacterium, Holdemanella, Klebsiella, Prevotella; disease duration: Alloprevotella, Butyrivibrio; BMI: Alloprevotella, Clostridium IV, Coprobacillus, Intestinimonas, Mitsuokella; medication: Faecalicoccus, Klebsiella, Parasutterella, Veillonella). However, the sample size of the different subgroups was small, and the review of the normalized counts and the relative abundance plots showing the presence of outliers suggested that the significant differences were rather statistical noise than true between-group differences. 
Table 1 Significantly differentially abundant taxa in patients with NT1 and controls

\begin{tabular}{|c|c|c|c|c|c|c|}
\hline Groups & Variable & $\begin{array}{l}\text { Taxon } \\
\text { level }\end{array}$ & Taxon designation & $\begin{array}{l}\text { Normalized mean } \\
\text { abundance }\end{array}$ & $\begin{array}{l}\text { Log } 2 \text { fold } \\
\text { change }\end{array}$ & $\begin{array}{l}\text { Adjusted } \\
p \text { Value }\end{array}$ \\
\hline $\begin{array}{l}\text { All C and all } \\
\text { NT1 }\end{array}$ & Diagnosis & OTU & Bacteroides Otu00012 & $1,058.259$ & +13.999 in C & $8.66 \mathrm{e}-16$ \\
\hline $\begin{array}{l}\text { All C and all } \\
\text { NT1 }\end{array}$ & Diagnosis & OTU & $\begin{array}{l}\text { Bacteria unclassified } \\
\text { Otu00078 }\end{array}$ & 109.098 & +8.144 in C & $3.18 \mathrm{e}-04$ \\
\hline $\begin{array}{l}\text { All C and all } \\
\text { NT1 }\end{array}$ & Diagnosis & OTU & Flavonifractor Otu00099 & 91.947 & +1.697 in NT1 & $1.64 \mathrm{e}-02$ \\
\hline $\begin{array}{l}\text { All C and all } \\
\text { NT1 }\end{array}$ & Diagnosis & OTU & $\begin{array}{l}\text { Bacteroidetes unclassified } \\
\text { Otu00102 }\end{array}$ & 62.685 & +10.048 in NT1 & $2.10 e-02$ \\
\hline $\begin{array}{l}\text { All C and all } \\
\text { NT1 }\end{array}$ & $\begin{array}{l}\text { Diagnosis corrected for } \\
\text { gender }\end{array}$ & OTU & Bacteroides Otu00012 & $1,058.259$ & +13.94 in $C$ & $3.78 \mathrm{e}-16$ \\
\hline $\begin{array}{l}\text { All C and all } \\
\text { NT1 }\end{array}$ & $\begin{array}{l}\text { Diagnosis corrected for } \\
\text { gender }\end{array}$ & OTU & $\begin{array}{l}\text { Bacteria unclassified } \\
\text { Otu00078 }\end{array}$ & 173.435010 & +8.01 in $C$ & $1.66 \mathrm{e}-04$ \\
\hline $\begin{array}{l}\text { All C and all } \\
\text { NT1 }\end{array}$ & $\begin{array}{l}\text { Diagnosis corrected for } \\
\text { gender }\end{array}$ & OTU & Flavonifractor Otu00099 & 91.946991 & +1.6376 in NT1 & $5.10 e-03$ \\
\hline
\end{tabular}

Abbreviations: $\mathrm{C}=$ controls; NT1 = narcolepsy type 1; OTU = operational taxonomic unit.

Variation of the significantly differentially abundant taxa without correction and after correction for gender. Log2FoldChange: estimation of the effect size (as a fold change) in log 2 scale and orientation of the variation; it represents how much does the abundance of the taxum of interest changes between groups (C and NT1). It also gives the orientation of this change.

\section{Predicted metabolic pathways}

PICRUSt2's predictions of microbial metabolic pathway abundances were used to infer potential differences between patients with NT1 and controls. We found no significant differences in predicted metabolic function patterns between patients with NT1 and controls.

\section{Discussion}

Here, we report an assessment of gut microbiota diversities and relative abundances in a well-characterized population of patients with NT1 compared with control subjects. We found no betweengroup differences for alpha diversity that quantifies both taxonomic richness and evenness, except for the Shannon index that correlated with NT1 disease duration. This result suggests that richness and evenness of microbial species may differ as a function of disease evolution in patients with NT1. We also reported a significant difference regarding the global bacterial community structure in NT1 vs controls, as assessed by beta diversity metrics. These results highlighted that the microbial community differs between patients with NT1 and controls, even after adjustment for BMI. We further explored with the DESeq2 analyses whether the community differences between groups are driven by changes in the abundance of certain taxa. Few microbial species were differentially abundant between patients and controls with one OTU among Bacteroides and one OTU among unclassified bacteria, which were decreased in patients, whereas an OTU among unclassified Bacteroidetes and one OTU among Flavonifractor were increased in patients with NT1 compared with controls. After adjustment for BMI, these differences did not remain significant and thus may not be associated with NT1 per se. Importantly, metabolic disturbances such as overweight/obesity are frequently associated with NT1: onethird of adults with NT1 are obese, and 50\% of children, with a rapid weight increase close to disease onset. ${ }^{3,35,36}$

Several studies have attempted to define what constitutes an "obese" vs a "healthy" gut microbiota. ${ }^{37,38}$ Generally, microbial diversity is an essential component to host health, and obese individuals have a lower bacterial diversity and decreased fecal microbial richness. ${ }^{39}$ The question whether changes in beta diversity and subtle differential community abundance between patients with NT1 and controls were directly related to the disease per se or to confounders such as BMI needs to be further explored.

Our global results may argue for a shift of the whole community structure in patients with NT1 compared with controls. Using the DESeq2 analyses, we found that the community differences between groups may relate to changes in abundance of few taxa; however, a complementary abundance analysis performed with the ALDEx2 at all taxon levels, found no between-group statistically significant results. ALDEx2 is a very conservative method, and it is not uncommon that results detected by DESeq 2 or other methods are not reproduced by ALDEx $2 .{ }^{23}$ The analysis of predicted metabolic pathways did not reveal functional differences between groups that would reflect the observed compositional differences. Finally, we did not find any association between microbial community structure and demographic and clinical characteristics in patients with NT1.

Although preliminary, the gut microbial diversity alteration we found here in NT1 reinforces the hypothesis of the important role of the environment in NT1 development and pathogenesis. It is now widely accepted by the scientific community that the 
Figure 3 Normalized counts and relative abundance plots between patients with NT1 and controls
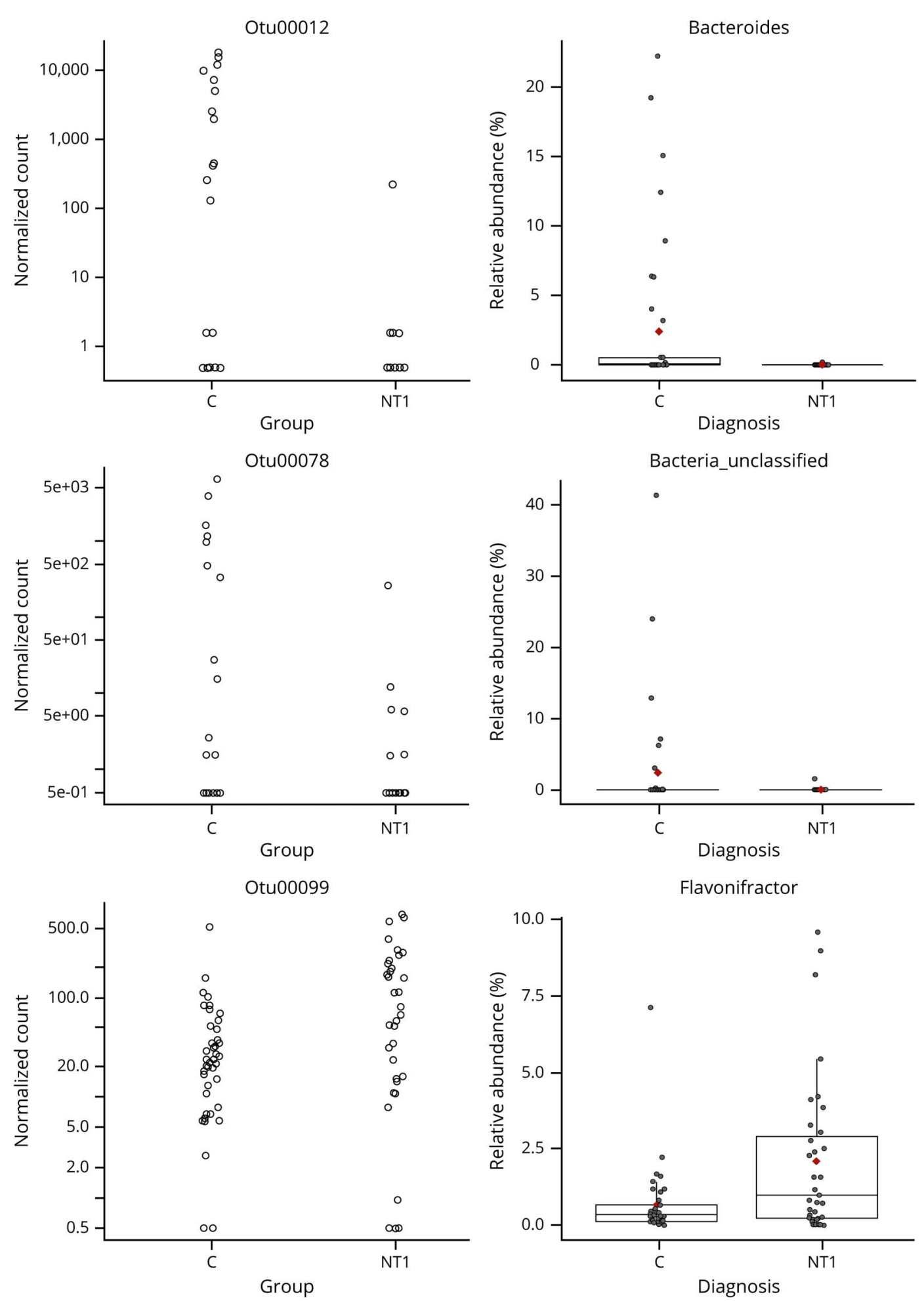

Visualization of differential abundance with plot of normalized counts and relative abundances of bacterial OTUs in the control (C) and narcolepsy (NT1) groups. Lower and upper hinge of the box: 1st and 3rd quartile; line: median; red diamond: mean. Three OTUs are represented: Bacteroides Otu00012, Bacteria unclassified Otu00078, and Flavonifractor Otu00099-the significantly differentially abundant OTUs (DESeq2 $p<0.1$ ) between control and NT1 groups after adjusting for gender. NT1 = Narcolepsy type 1; OTU = operational taxonomic unit.

immune system is involved in the death of ORX neurons. ${ }^{3,40}$ Complex interactions have been established between the gut microbiota and the CNS, and gut-brain interactions may occur through immune-mediated inflammatory pathways. ${ }^{18,19}$ The gut microbiota plays a key role in maintaining the integrity of the intestinal epithelium and the mucosal barrier. ${ }^{39}$ Several other 
roles of the gut microbiota were highlighted with modulation of CNS inflammation, regulatory cells from both $\mathrm{T}$ and $\mathrm{B}$ cell lineages, and changes in cytokine activities and microglia activation, all potential players involved in the pathogenesis of NT1. ${ }^{18,19,41-43}$ Hence, subtle changes in the microbiome may modulate risk of NT1 in genetically predisposed individuals (carrying the HLA DQB1*06:02 allele) as already reported in several neuro(auto)immune disorders such as MS. ${ }^{18,44}$

At this point, it remains unclear whether the changes in the gut microbiota are robust in NT1 and whether these changes, if confirmed, are involved in disease causation or are rather a consequence of the disease. Regarding the latter, it also cannot be ruled out that latent identified (such as BMI) or unidentified clinical confounders are involved, meaning that observed beta diversity and taxon abundance differences may not even be a consequence of the disease state itself. In addition, how microbiota affect changes in (auto)immunity related to NT1, symptom burden, disease progression, and drug treatment responses remains to be further established. Whether the modulation of the microbiome can lead to either exacerbation or improvement of symptoms in NT1, especially close to disease onset, remains also to be investigated.

This study has several strengths and limitations. We included well-characterized patients with NT1 comparable with control subjects about gender and age, with recruitment of subjects within the same geographical region and from the same period. None of the participants had comorbid immune diseases, an expected condition in NT1; this disorder having a unique pathophysiology. ${ }^{45}$ Experimental design with standardized collection and storage; molecular analysis technology and methods for data analysis were performed according to the best practice methods, with strong precautions to minimize batch effects and contamination. ${ }^{46,47}$ The main limitation of our study is the small sample size. However, NT1 affects only 1 in 2,000 people worldwide, so the rarity of this sleep disorder justifies the present report of the first small-scale exploratory study of the gut microbiota in NT1. Unfortunately, owing to heavily tailed zeroinflated distributions of bacterial abundances and the multivariate nature of the data, power calculations for microbiome studies are challenging, and no consensus exist on how they should be conducted. The question of whether the difference in beta diversity and subtle changes in relative abundance of microbial taxa between narcolepsy and control samples reflects an underlying diversity or sampling bias remains to be confirmed. Patients with NT1 had a higher BMI than control subjects, which may have introduced bias into the analysis despite our model adjustments. In addition, our study lacks assessments of lifestyle, diet as well as gastrointestinal discomfort in our subjects, and questionnaires on gut and on depressive symptoms, which would have further improved confounder adjustment. Indeed, a recent study reported a large spectrum of clinical autonomic dysfunction in NT1 with impairment in the gastrointestinal area that may modify the gut microbial composition. ${ }^{48}$ Moreover, most of the patients were recruited long after disease onset, but long delays between symptoms onset and diagnosis remain unfortunately the rule for this rare disease. ${ }^{49}$ Therefore, possible transitory microbiota alterations, more pronounced during the autoimmune processes at disease initiation, may have become undetectable during the follow-up period. Owing to the lack of power in the analysis of subgroups of patients based on clinical characteristics, we cannot at this stage discern the effects of endophenotypes, comorbidities, and of medications taken by patients with NT1 on abundances in the microbial community. Finally, our results cannot be considered as definite identification of specific gut microbial community structure alterations in NT1. We need larger sample sizes in the future to obtain more reliable estimates, and different study designs with longitudinal studies and randomized controlled trials with multiple time points of the same subjects to elucidate potential causal relationships and to find out if targeting the microbiome can yield novel therapeutic strategies.

To conclude, we provide evidence for differences in gut microbial communities in NT1. However, our preliminary results cannot be considered a definite identification of specific microbiome-based biomarkers in narcolepsy. Further larger, and preferably longitudinal, multiomics studies are required to replicate our findings, to elucidate the relationship between the gut microbiota and NT1, and to determine the role of the microbiome in the development of the disease, if any.

\section{Acknowledgment}

The authors thank the personnel of the DNA Sequencing and Genomics Laboratory for performing the DNA isolations and NGS sequencing. The authors thank all collaborators within the National Reference Center for Narcolepsy, in Montpellier, France. The authors are indebted to all the participants of the study, narcoleptic patients and controls.

\section{Study funding}

ANR (Agence Nationale de la Recherche): this was not an industry-supported study.

\section{Disclosure}

F. Scheperjans reports grants from Finnish Medical Foundation; grants from Academy of Finland; during the conduct of the study, personal fees and nonfinancial support from AbbVie; personal fees and nonfinancial support from UCB; nonfinancial support from Nordicinfu Care; nonfinancial support from Medtronic; other from NeuroInnovation Oy; personal fees and nonfinancial support from Herantis Pharma; nonfinancial support from Global Kinetics Corporation; personal fees and nonfinancial support from Zambon; personal fees from Orion, nonfinancial support from Abbott; personal fees and nonfinancial support from LivaNova; and personal fees from Axial Biotherapeutics, outside the submitted work. In addition, F. Scheperjans has a patent FI127671B issued, a patent US10139408B2 issued, a patent EP3149205A4 pending, and a patent US16/186,663 pending. P. Pereira has a patent FI127671B issued, a patent US10139408B2 issued, a patent EP3149205A4 pending, and a patent US16/186,663 pending. Y. Dauvilliers received funds for seminars, board engagements, and travel to conferences by UCB Pharma, Jazz, Theranexus, Avadel, Idorsia, and 
Bioprojet. L. Barateau received funds for travel to conferences by UCB Pharma. A. Lecomte, L. Paulin, and P. Auvinen report no disclosure. Go to Neurology.org/NN for full disclosures.

\section{Publication history}

Received by Neurology: Neuroimmunology \& Neuroinflammation July 2, 2020. Accepted in final form August 31, 2020.

\section{Appendix Authors}

\begin{tabular}{|c|c|c|}
\hline Name & Location & Contribution \\
\hline $\begin{array}{l}\text { Alexandre } \\
\text { Lecomte, } \\
\text { MSc }\end{array}$ & $\begin{array}{l}\text { University of } \\
\text { Helsinki, } \\
\text { Finland }\end{array}$ & $\begin{array}{l}\text { Data acquisition, drafting/revising } \\
\text { the manuscript, study concept or } \\
\text { design, analysis or interpretation of } \\
\text { data, statistical analysis, study } \\
\text { supervision, and contribution of vital } \\
\text { reagents/tools/patients }\end{array}$ \\
\hline
\end{tabular}

\begin{tabular}{|c|c|c|}
\hline $\begin{array}{l}\text { Lucie } \\
\text { Barateau, } \\
\text { MD }\end{array}$ & $\begin{array}{l}\text { University of } \\
\text { Montpellier, } \\
\text { France }\end{array}$ & $\begin{array}{l}\text { Data acquisition, drafting/revising } \\
\text { the manuscript, and analysis or } \\
\text { interpretation of data }\end{array}$ \\
\hline $\begin{array}{l}\text { Pedro } \\
\text { Pereira, PhD }\end{array}$ & $\begin{array}{l}\text { University of } \\
\text { Helsinki, } \\
\text { Finland }\end{array}$ & $\begin{array}{l}\text { Drafting/revising the manuscript, } \\
\text { study concept or design, analysis or } \\
\text { interpretation of data, statistical } \\
\text { analysis, and study supervision }\end{array}$ \\
\hline $\begin{array}{l}\text { Lars Paulin, } \\
\text { MSc }\end{array}$ & $\begin{array}{l}\text { University of } \\
\text { Helsinki, } \\
\text { Finland }\end{array}$ & $\begin{array}{l}\text { Data acquisition and drafting/ } \\
\text { revising the manuscript }\end{array}$ \\
\hline $\begin{array}{l}\text { Petri } \\
\text { Auvinen, } \\
\text { PhD }\end{array}$ & $\begin{array}{l}\text { University of } \\
\text { Helsinki, } \\
\text { Finland }\end{array}$ & $\begin{array}{l}\text { Data acquisition, drafting/revising } \\
\text { the manuscript, study concept or } \\
\text { design, analysis or interpretation of } \\
\text { data, and study supervision }\end{array}$ \\
\hline $\begin{array}{l}\text { Filip } \\
\text { Scheperjans, } \\
\text { MD }\end{array}$ & $\begin{array}{l}\text { University of } \\
\text { Helsinki, } \\
\text { Finland }\end{array}$ & $\begin{array}{l}\text { Drafting/revising the manuscript, } \\
\text { study concept or design, analysis or } \\
\text { interpretation of data, and study } \\
\text { supervision }\end{array}$ \\
\hline $\begin{array}{l}\text { Yves } \\
\text { Dauvilliers, } \\
\text { MD }\end{array}$ & $\begin{array}{l}\text { University of } \\
\text { Montpellier, } \\
\text { France }\end{array}$ & $\begin{array}{l}\text { Data acquisition, drafting/revising } \\
\text { the manuscript, study concept or } \\
\text { design, analysis or interpretation of } \\
\text { data, study supervision, and obtain } \\
\text { Funding }\end{array}$ \\
\hline
\end{tabular}

\section{References}

1. Dauvilliers Y, Arnulf I, Mignot E. Narcolepsy with cataplexy. Lancet 2007;369: 499-511.

2. Scammell TE. Narcolepsy. N Engl J Med 2015;373:2654-2662.

3. Bassetti CLA, Adamantidis A, Burdakov D, et al. Narcolepsy-clinical spectrum, aetiopathophysiology, diagnosis and treatment. Nat Rev Neurol 2019;15:519-539.

4. Peyron C, Faraco J, Rogers W, et al. A mutation in a case of early onset narcolepsy and a generalized absence of hypocretin peptides in human narcoleptic brains. Nat Med 2000;6:991-997.

5. Thannickal TC. Reduced number of hypocretin neurons in human narcolepsy. Neuron 2000;27:469-474.

6. Barateau L, Liblau R, Peyron C, Dauvilliers Y. Narcolepsy type 1 as an autoimmune disorder: evidence, and implications for pharmacological treatment. CNS Drugs 2017;31:821-834.

7. Barateau L, Dauvilliers Y. Recent advances in treatment for narcolepsy. Ther Adv Neurol Disord 2019;12:1756286419875622.

8. Kornum BR, Knudsen S, Ollila HM, et al. Narcolepsy. Nat Rev Dis Primers 2017;3:16100

9. Latorre D, Kallweit U, Armentani E, et al. T cells in patients with narcolepsy target self-antigens of hypocretin neurons. Nature 2018;562:63-68.

10. Pedersen NW, Holm A, Kristensen NP, et al. CD8+ T cells from patients with narcolepsy and healthy controls recognize hypocretin neuron-specific antigens. Nat Commun 2019;10:837.

11. Luo G, Ambati A, Lin L, et al. Autoimmunity to hypocretin and molecular mimicry to flu in type 1 narcolepsy. Proc Natl Acad Sci U S A 2018;115:E12323-E12332.

12. Liblau RS, Vassalli A, Seifinejad A, Tafti M. Hypocretin (orexin) biology and the pathophysiology of narcolepsy with cataplexy. Lancet Neurol 2015;14:318-328.
13. Dauvilliers $\mathrm{Y}$, Arnulf I, Lecendreux M, et al. Increased risk of narcolepsy in children and adults after pandemic H1N1 vaccination in France. Brain 2013;136:2486-2496.

14. Partinen M, Kornum BR, Plazzi G, Jennum P, Julkunen I, Vaarala O. Narcolepsy as an autoimmune disease: the role of $\mathrm{H} 1 \mathrm{~N} 1$ infection and vaccination. Lancet Neurol 2014;13:600-613.

15. Ding Q, Li J, Xiao F, Zhang C, Dong X, Han F. Anti-Streptococcal antibodies in Chinese patients with type-1 narcolepsy. Sleep Med 2020;72:37-40.

16. International Human Genome Sequencing Consortium. Finishing the euchromatic sequence of the human genome. Nature 2004;431:931-945.

17. Qin J, Li R, Raes J, et al. A human gut microbial gene catalogue established by metagenomic sequencing. Nature 2010;464:59-65.

18. Iannone LF, Preda A, Blottière HM, et al. Microbiota-gut brain axis involvement in neuropsychiatric disorders. Expert Rev Neurother 2019;19:1037-1050.

19. Cryan JF, O’Riordan KJ, Sandhu K, Peterson V, Dinan TG. The gut microbiome in neurological disorders. Lancet Neurol 2020;19:179-194.

20. Tremlett H, Bauer KC, Appel-Cresswell S, Finlay BB, Waubant E. The gut microbiome in human neurological disease: a review. Ann Neurol 2017;81:369-382.

21. Böttger EC. Rapid determination of bacterial ribosomal RNA sequences by direct sequencing of enzymatically amplified DNA. FEMS Microbiol Lett 1989;53:171-176.

22. AASM: American Academy of Sleep Medicine. ICSD-3: International Classification of Sleep Disorders, 3rd ed. Chest 2014;146:1387-1394.

23. Aho VTE, Pereira PAB, Voutilainen S, et al. Gut microbiota in Parkinson's disease: temporal stability and relations to disease progression. EBioMedicine 2019;44:691-707.

24. Pereira PAB, Aho VTE, Paulin L, Pekkonen E, Auvinen P, Scheperjans F. Oral and nasal microbiota in Parkinson's disease. Parkinsonism Relat Disord 2017;38:61-67.

25. Somervuo P, Koskinen P, Mei P, Holm L, Auvinen P, Paulin L. BARCOSEL: a tool for selecting an optimal barcode set for high-throughput sequencing. BMC Bioinformatics 2018;19:257.

26. Martin M. Cutadapt removes adapter sequences from high-throughput sequencing reads. EMBnet J 2011;17:10-12.

27. Kozich JJ, Westcott SL, Baxter NT, Highlander SK, Schloss PD. Development of a dualindex sequencing strategy and curation pipeline for analyzing amplicon sequence data on the MiSeq Illumina sequencing platform. Appl Environ Microbiol 2013;79:5112-5120.

28. R Core Team, 2020. R: A language and environment for statistical computing. $\mathrm{R}$ Foundation for Statistical Computing, Vienna, Austria. Available at: URL https:// www.R-project.org/.

29. Oksanen J, Blanchet F G, Friendly M, et al., 2019. Vegan: Community Ecology Package. R package version 2.5-6. Available at: https://CRAN.R-project.org/ package $=$ vegan.

30. Love MI, Huber W, Anders S. Moderated estimation of fold change and dispersion for RNA-seq data with DESeq2. Genome Biol 2014;15:550.

31. Fernandes AD, Macklaim JM, Linn TG, Reid G, Gloor GB. ANOVA-like differential gene expression analysis of single-organism and meta-RNA-seq. PLoS one 2013;8: e67019.

32. Langille MGI, Zaneveld J, Caporaso JG, et al. Predictive functional profiling of microbial communities using 16S rRNA marker gene sequences. Nat Biotechnol 2013; 31:814-821.

33. Douglas GM, Maffei VJ, Zaneveld J, et al. PICRUSt2: an improved and extensible approach for metagenome inference. BioRxiv 2019:672295.

34. Parks DH, Tyson GW, Hugenholtz P, Beiko RG. STAMP: statistical analysis of taxonomic and functional profiles. Bioinformatics 2014;30:3123-3124.

35. Inocente $\mathrm{CO}$, Lavault $\mathrm{S}$, Lecendreux $\mathrm{M}$, et al. Impact of obesity in children with narcolepsy. CNS Neurosci Ther 2013;19:521-528.

36. Schuld A, Hebebrand J, Geller F, Pollmächer T. Increased body-mass index in patients with narcolepsy. Lancet 2000;355:1274-1275.

37. Sze MA, Schloss PD. Looking for a signal in the noise: revisiting obesity and the microbiome. mBio 2016;7:e01018-16.

38. Ley RE, Bäckhed F, Turnbaugh P, Lozupone CA, Knight RD, Gordon JI. Obesity alters gut microbial ecology. Proc Natl Acad Sci U S A 2005;102:11070-11075.

39. Le Chatelier E, Nielsen T, Qin J, et al. Richness of human gut microbiome correlates with metabolic markers. Nature 2013;500:541-546.

40. Kornum BR. Narcolepsy type 1: what have we learned from immunology?, Sleep, 2020, zsaa055. Available at: https://doi.org/10.1093/sleep/zsaa055.

41. Braniste $\mathrm{V}, \mathrm{Al}$-Asmakh $\mathrm{M}$, Kowal C, et al. The gut microbiota influences blood-brain barrier permeability in mice. Sci Transl Med 2014;6:263ra 158.

42. Lecendreux M, Libri V, Jaussent I, et al. Impact of cytokine in type 1 narcolepsy: role of pandemic H1N1 vaccination? J Autoimmun 2015;60:20-31.

43. Nguyen $\mathrm{XH}$, Dauvilliers $\mathrm{Y}$, Quériault $\mathrm{C}$, et al. Circulating follicular helper $\mathrm{T}$ cells exhibit reduced ICOS expression and impaired function in narcolepsy type 1 patients. J Autoimmun 2018;94:134-142.

44. Jangi S, Gandhi R, Cox LM, et al. Alterations of the human gut microbiome in multiple sclerosis. Nat Commun 2016;7:12015.

45. Barateau L, Lopez R, Arnulf I, et al. Comorbidity between central disorders of hypersomnolence and immune-based disorders. Neurology 2017;88:93-100.

46. Knight R, Vrbanac A, Taylor BC, et al. Best practices for analysing microbiomes. Nat Rev Microbiol 2018;16:410-422.

47. Debelius J, Song SJ, Vazquez-Baeza Y, Xu ZZ, Gonzalez A, Knight R. Tiny microbes, enormous impacts: what matters in gut microbiome studies? Genome Biol 2016;17:217.

48. Barateau L, Chenini S, Evangelista E, Jaussent I, Lopez R, Dauvilliers Y. Clinical autonomic dysfunction in narcolepsy type 1. Sleep 2019;42:zsz187.

49. Luca G, Haba-Rubio J, Dauvilliers Y, et al. Clinical, polysomnographic and genomewide association analyses of narcolepsy with cataplexy: a European Narcolepsy Network study. J Sleep Res 2013;22:482-495. 


\section{Neurology \\ Neuroimmunology \& Neuroinflammation}

Gut microbiota composition is associated with narcolepsy type 1

Alexandre Lecomte, Lucie Barateau, Pedro Pereira, et al.

Neurol Neuroimmunol Neuroinflamm 2020;7;

DOI 10.1212/NXI.0000000000000896

This information is current as of October 9, 2020

\section{Updated Information \& Services}

References

Subspecialty Collections

Permissions \& Licensing

Reprints including high resolution figures, can be found at:

http://nn.neurology.org/content/7/6/e896.full.html

This article cites 45 articles, 4 of which you can access for free at: http://nn.neurology.org/content/7/6/e896.full.html\#\#ref-list-1

This article, along with others on similar topics, appears in the following collection(s):

Narcolepsy

http://nn.neurology.org//cgi/collection/narcolepsy

Information about reproducing this article in parts (figures,tables) or in its entirety can be found online at:

http://nn.neurology.org/misc/about.xhtml\#permissions

Information about ordering reprints can be found online: http://nn.neurology.org/misc/addir.xhtml\#reprintsus

Neurol Neuroimmunol Neuroinflamm is an official journal of the American Academy of Neurology.

Published since April 2014, it is an open-access, online-only, continuous publication journal. Copyright

Copyright $\odot 2020$ The Author(s). Published by Wolters Kluwer Health, Inc. on behalf of the American

Academy of Neurology.. All rights reserved. Online ISSN: 2332-7812.

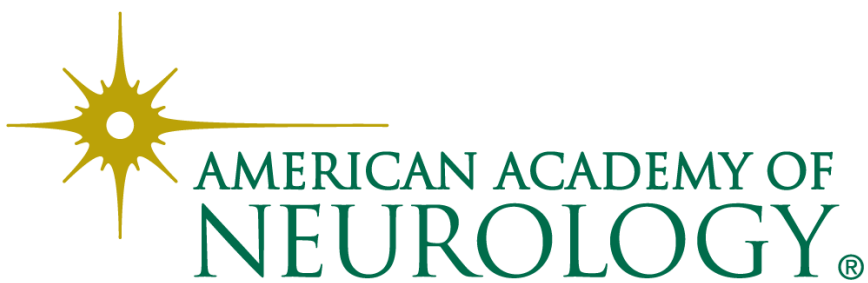

